
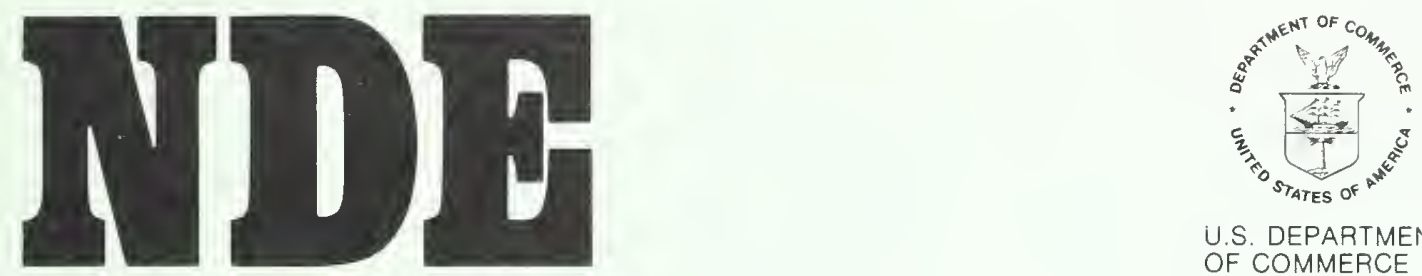

U.S. DEPARTMENT
OF COMMERCE

September, 1979

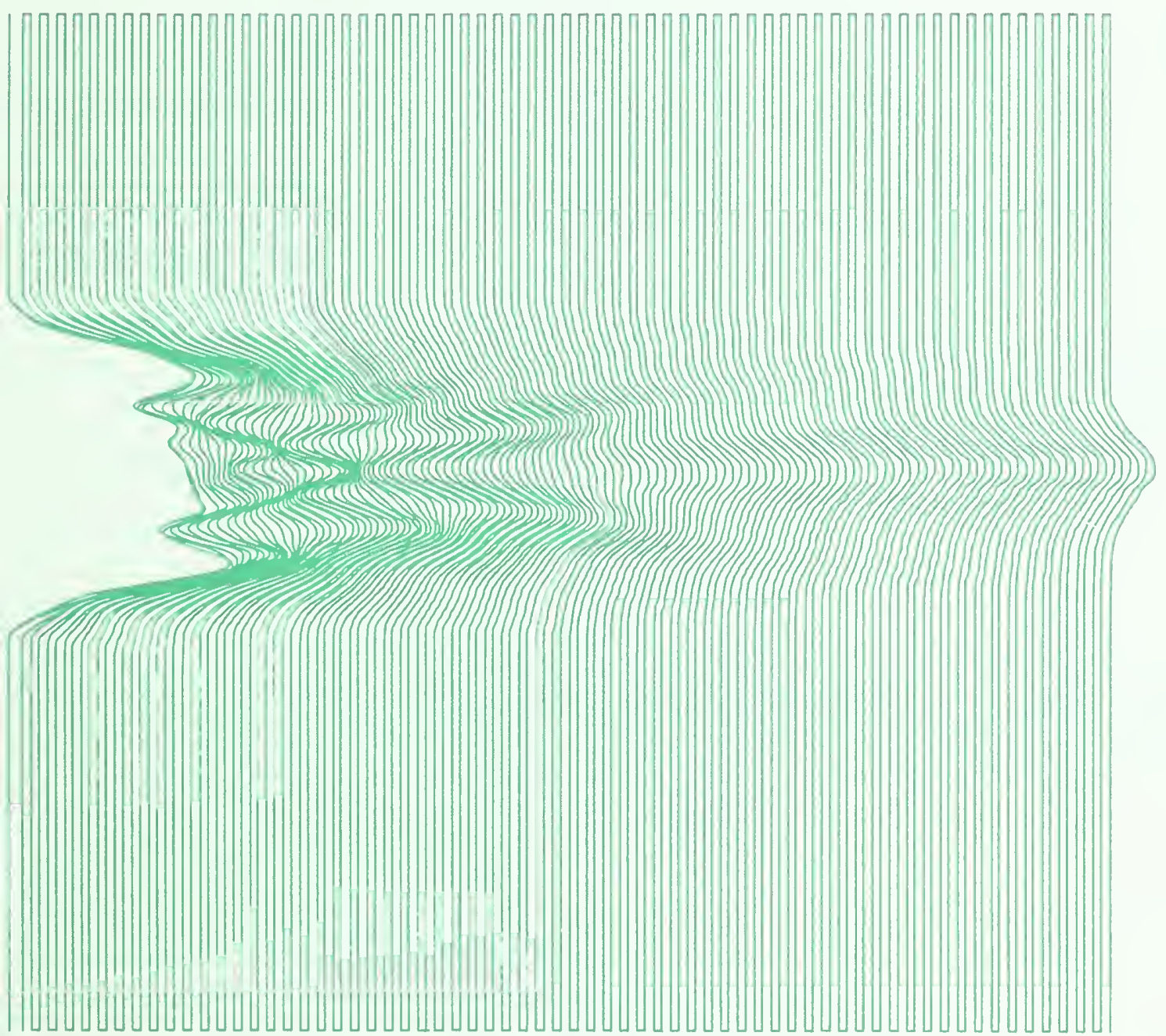


Introduction. Today, many material failures are prevented thanks to a system of test methods that detects flaws and defects in materials before the failures occurin fact, before the materials are put into service. Called "nondestructive evaluation (NDE)," the system is potentially applicable to inspection of such high technology products as nuclear reactors and supersonic aircraft as well as to inspection of more consumeroriented products such as pacemakers and parts of automobiles.

Actually, NDE is not a single method, but rather a name used to describe a variety of techniques that can be used to examine materials without destroying or damaging the material during the examination procedure. Some of these methods, $x$-radiography for example, have been used for many years. Others, such as neutron radiography and acoustic emission, are just now coming into wider use as NDE methods.

Despite the increasing use of NDE methods for practical purposes, there are definite needs to improve the measurement methods and to relate measurements to the actual performance of the material. The National Bureau of Standards has established an Office of Nondestructive Evaluation to assist industry and government agencies in improving the reliability of materials and structures; NBS is working to help industry develop methods for

Cover: An analog representation of an intensity field pattern of a 10 $\mathrm{MHz}$ ultrasonic transducer. accurate and reproducible NDE measurements. This includes technical investigations, development of standards (both measurement standards and procedural documents), characterization of instruments, and assessments of the meaning of NDE measurements in relation to material performance. The main emphasis of the NBS program is on the needs for improved measurements and calibration standards and procedures for many of the NDE methods commonly used in industry.

At the Bureau, the NDE program is coordinated by the National Measurement Laboratory. Strong interactions with industry, technical societies, and government agencies have been established in order to solicit their advice on needs and to aid in technology transfer for developed methods and standards.

Examples of NBS research in several areas of NDE are described below.

\section{Acoustic-uptrasonic Programs.} Work is in progress to develop methods for calibration of ultrasonic and acoustic emission transducers. Spectral characteristics, beam profile, and total sound power measurements are being studied. Some transducer calibration services are now available.

NBS researchers are studying ultrasonic test blocks, in a program that had initial, partial funding from the Air Force, Army, and the National Aeronautics and Space Administration, to determine the reasons for variability of these metal calibration blocks. A calibration service for aluminum ultrasonic reference blocks is available. Further directions for this effort include the development of material-independent test blocks and the development of well-characterized fatigue cracks that could serve as a calibration for many NDE tests.

Instrumentation development work in both ultrasonics and acoustic emission is also in progress. This includes development of improved signal-to-noise ratio systems by methods such as signal averaging and pulse compression. A program to characterize the important variables in ultrasonic instrumentation is in progress. Imaging instrumentation is also under development.

These NDE methods are being applied to metals, ceramics, polymers, building materials, and electronic components. Specific application studies involve ultrasonic inspection of pipeline welds for the Department of Transportation and the analysis of ultrasonic inspection data for the U.S. Nuclear Regulatory Commission.

A program to develop a theore ical basis for acoustic emission spectral analysis to characterize moving cracks or defects is in progress, partially funded by the Electric Power Research Institute. This program includes work for improved transducer calibration.

Badiography. Current programs involve work in both neutron and $x$-radiography. The $x$-ray program includes investigations of standards for the measurement of spatial resolution in radiographic systems, for the determination of response of $x$-ray film and for the characterization of real-time fluoroscopic systems. Developments 
in progress include work on improved $\mathrm{x}$-ray screens and determination of scattered radiation content and its effect on radiographic detectors and systems.

The neutron radiographic studies are made primarily with a thermal neutron radiographic facility at the NBS research reactor. Work has been carried out with a 3 MeV Van de Graaff accelerator and a $100 \mathrm{MeV}$ linear accelerator. A recommended practice for thermal neutron radiography is being developed in collaboration with the American Society for Testing and Materials. Standards for characterizing neutron beams for radiography and gaging are under investigation. NBS scientists have investigated the use of threedimensional thermal neutron radiography and have shown the application of this inspection procedure to nuclear fuel subassemblies, batteries, and art objects. Recent work for the U.S. Navy concerns an evaluation of practical neutron sources for neutron radiography.

\section{Electromagnetic Methods.}

- Visual. NBS scientists are examining methods for the measurement of visual acuity under typical NDE inspection conditions. This includes the effects of subdued lighting common in radiographic reading rooms and of the dark booth situations typically

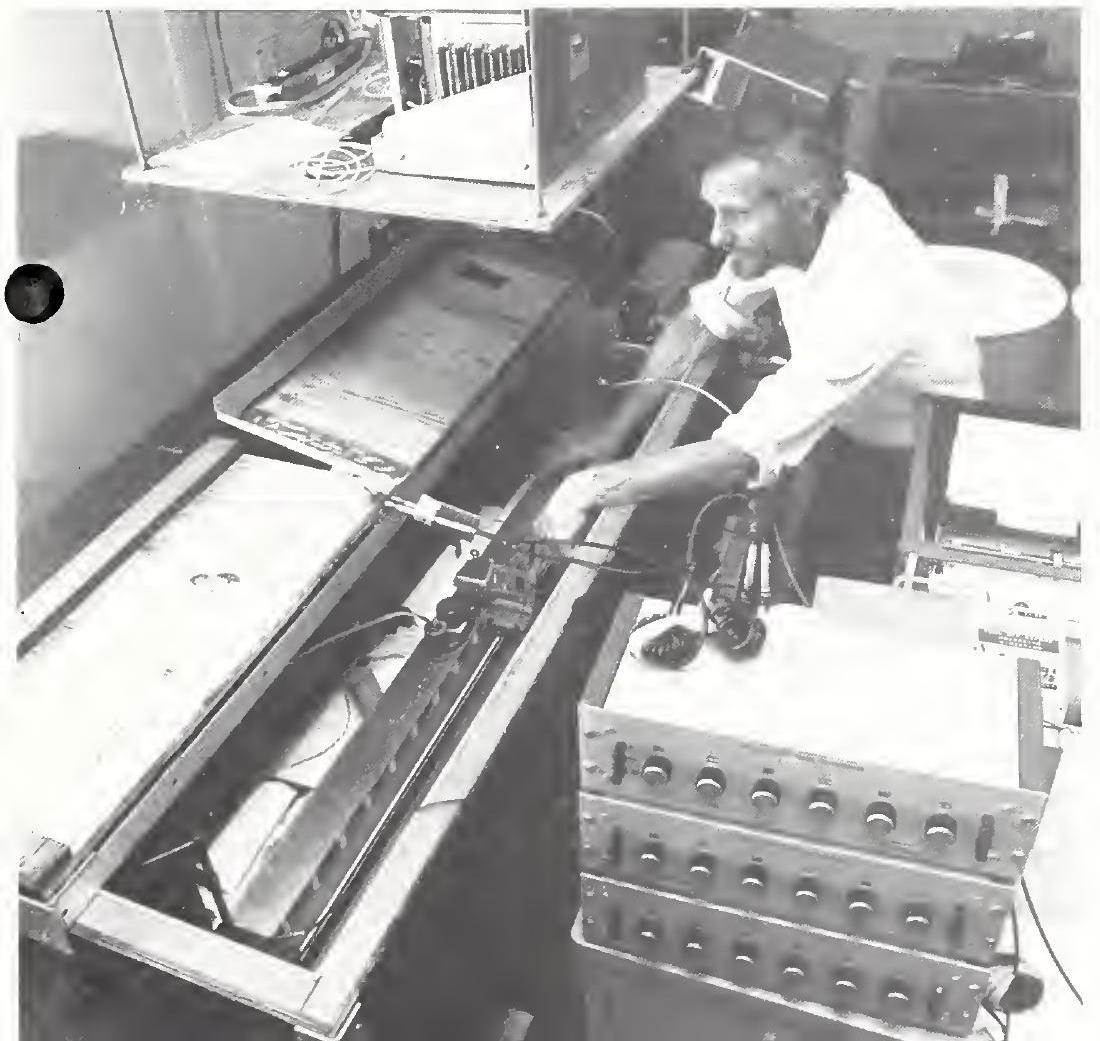

used in fluorescent penetrant and magnetic particle inspection.

The program will characterize test methods used in NDE where the human eye is an integral part of the system. Visual parameters critical to the ability of people to detect and judge visual indications of defects will be identified. These accomplishments will lead to recommendations for improved visual acuity measurement methods.

- Optical. Optical methods utilizing reflected and scattered light are being investigated for the detection of surface defects and for the measurement of surface roughness. A review of optical NDE methods is in preparation. Consideration is being given to

A temperature controlled tacility for the measurement of electrical conductivity. Both ac and dc conductivity can be measured. A laser system is used to determine the distance between measurement points. 
the need for standards in holographic NDE.

- Electrical Eddy-Currents. Facilities for dc and ac electrical conductivity measurements have been completed as the first stage of a new program in electrical and eddy-current methods. Procedures have been established for the measurement of conductivity over the range of 1-100 percent of the International Annealed Copper Standard. Methods for the calibration of eddy-current test equipment aie under investigation.

- Magnetic Methods. This program is particularly concerned with improving measurements for magnetic particle testing. The work includes efforts to determine the uniformity of magnetization within the inspected part and measurements of magnetic leakage flux.

- Microwave Methods. Microwave measurements are being used to determine physical properties of materials. The NDE Program utilizes microwaves to measure moisture content of concrete. These measurements relate to the strength of the material.

This represents one area in which NDE methods are being explored for applications in the building industry. Future work to measure moisture content of other building materials is planned.

Penetrant Testing. NBS scientists are investigating the feasibility of preparing a master crack calibration plate for the evaluation of penetrant sensitivity. Electroforming methods are being used for the preparation of well-characterized, reproducible, inexpensive crack plates. The fluids and particles used for penetrant testing are also of interest. Brightness measurements of fluorescent penetrants are planned, along with work on measurements of key properties of the fluids.

\section{Wear Debris Analysis. Detection} of worn metal in lubricants in mechanical machinery is now used in both military and civilian programs to determine the proper time for engine, bearing, and transmission overhaul. This method is now being expanded in a current NBS program, partially funded by the U.S. Navy, in which the wear debris particles in the lubricant are detected, sized, and examined in order to determine where and by what mechanism wear is occurring. Magnetic methods for obtaining size distributions of wear particles are used. X-ray microanalysis techniques have been developed for particles in the micrometer range. The techniques offer increased sensitivity for engine condition monitoring compared to conventional SOAP methods.

Thermal-Infrared. A recently completed program resulted in the development of a method for the nondestructive evaluation of batteries used in critical assemblies such as cardiac pacemakers. A microcalorimeter capable of measurements in the 0.2 to 1000 microwatt range is used to measure heat generated in batteries and, in some cases, pacemakers under a variety of conditions. Heat generation by new and partially discharged batteries is measured under no-load conditions as a measure of self-discharge. The work has resulted in a nondestructive method to determine power cell quality. Additional work on infrared NDE systems is being considered.

The results of these research activities are disseminated to the NDE community by a variety of media including publications, topical symposia and workshops, and the participation of the NDE staff in the related activities of several professional societies and committees. Some selected recent publications are listed on the back cover of this brochure; a comprehensive bibliography of NBS NDE publications and annual reports of the program are available. Attendance at the Bureau's symposia is generally open to all interested parties. Additional information on these and other NDE activities m be obtained from the Chief, Office of Nondestructive Evaluation, $\mathrm{Na}$ tional Measurement Laboratory, National Bureau of Standards, Washington, D. C. 20234; telephone (301) 921-3331. 


\begin{tabular}{|c|c|c|c|c|}
\hline Resthod & $\begin{array}{l}\text { Characteristics } \\
\text { Detected }\end{array}$ & Advantages & Limilax̂ions & $\begin{array}{l}\text { Example } \\
\text { of Use }\end{array}$ \\
\hline Umbrasonics & $\begin{array}{l}\text { Changes in acoustic } \\
\text { impedance caused by } \\
\text { cracks, nonbonds, in- } \\
\text { clusions, or interfaces. }\end{array}$ & $\begin{array}{l}\text { Can penetrate thick } \\
\text { materials; excellent for } \\
\text { crack detection; can } \\
\text { be automated. }\end{array}$ & $\begin{array}{l}\text { Normally requires } \\
\text { coupling to material } \\
\text { either by contact to } \\
\text { surface or immersion } \\
\text { in a fluid such as } \\
\text { water. }\end{array}$ & $\begin{array}{l}\text { Adhesive as- } \\
\text { semblies for } \\
\text { bond integrity. }\end{array}$ \\
\hline
\end{tabular}

\section{Pediography}

Changes in density from voids, inclusions, material variations; placement of internal parts.
Can be used to inspect wide range of materials and thicknesses; versatile; film provides record of inspection.
Radiation safety requires precautions; expensive; detection of cracks can be difficult.
Pipeline welds for penetration, inclusions, voids.

\section{Visugato} Optical
Surface characteristics such as finish, scratches, cracks, or color; strain in transparent materials.
Often convenient; can be automated.
Can be applied only to surfaces, through surface openings, or to transparent material.
Paper, wood, or metal for surface finish and uniformity.
Changes in electrical conductivity caused by material variations, cracks, voids, or inclusions.
Readily automated; moderate cost.
Limited to electrically conducting materials; limited penetration depth.
Heat exchanger tubes for wall thinning and cracks.
Liquid Penetrant
Surface openings due to cracks, porosity, seams, or folds.
Inexpensive, easy to use, readily portable, sensitive to small surface flaws.

Inexpensive, sensitive both to surface and near-surface flaws.
Flaw must be open to surface. Not useful on porous materials.
Turbine blades for surface cracks or porosity.

Railroad

Limited to ferromagnetic material; surface preparation and postinspection demagnetization may be required. wheels for cracks.
Leakage magnetic flux caused by surface or near-surface cracks, voids, inclusions, material or geometry changes. 
Selected Publications

"Annual Report 1978; Office of Nondestructive Evaluation," $\mathrm{H}$ Berger and L. Mordfin, editors, NBSIR 78-1581 (1979)

'NDE Publications: 19721977," L. Mordfin, editor, NBSIR 78-1557 (1978).

'Calibrations and Standards for Nondestructive Testing," $\mathrm{H}$ Berger and L. Mordfin, Materia/s Evaluation, 36, 36-39 (1978).

" Nondestructive Measurements -How Good are They?," H. Berger, Materia/s Evaluation 34 (1), p. 18A (1976)

"A Review of Nondestructive Evaluation Opportunities," R. M. Thomson, Standardization News, 3 (3), 8 (1975).

'Nondestructive Testing Standards: A Review" (H. Berger, ed), ASMT STP 624, 350 pp. (Am. Soc. Testing and Materials, Philadelphia, PA 19103, 1977).

'Acoustic Emission: Some Applications of Lamb's Problem." F. R. Breckenridge, C. E. Tchiegg, M. Greenspan, J. ACcoust, Soc. Am. 57 (3), 626-631 (1975).

'Acoustic Emission in Brittle Materials," A. G. Evans, M. Linzer, Ann. Rev. Mater, Sci. 7. 179-208 (1977)
An Approach to Acoustic Emission Signal Analysis: Theory and Experiment," N. N. Hsu, J. A.

Simmons, S. C. Hardy, Materia/s Evaluation 35 (10), 100-106 (1977)

'Procedures for the Calibration of ASTM E127-Type Uitrasonic Reference Blocks," D. J. Chwirut, G. F. Sushinsky, D. G. Eitzen, NBS Tech. Note 924 (1976). Order from Govt. Printing Office, Washington, DC 20402 as C13.46:924.

"Improved UItrasonic Standard Reference Blocks," G. F. Sushinsky, D. G. Eitzen, D. J. Chwirut, C. J. Bechtoldt, A. W. Ruff, NBSiR 76-984 (1976). Drder from Natl. Tech. Information Service Springfield, VA 22151 as PB262020

"The Evaluation of Search Units Used for Ultrasonic Reference Block Calibrations," D. J. Chwirut and G. D. BosweII, NBSIR 781454 (1978)

'UItrasonic-Transducer Power Output by Modulated Radiation Pressure," M. Greenspan F. R. Breckenridge, C. E. Tschiegg, J. Acoust. Soc. Am. 63 (4), 10311038 (1978).

"Uitrasonic Transducer Characterization at the NBS," E. B. Miller and D. G. Eitzen, IEEE Trans. Sonics and Uitrasonics, 26 (1), 28-37 (1979).

'An NDT Method Using Piezoelectric Polymer Transducers and Computerized Vibrational Spectroscopy," D. H. Reneker, S. Edelman, A. S. DeReggi and D. L. Vanderhart, NDT international, 11 (1) $15-16$ (1978).
"Expanding-Aperature Annual Array," D. R. Dietz, S. I. Parks and $M$. Linzer, Ultrasonic Imaging, 1 (1) 56-75 (1979).

"Ultrasonic Reflectivity Tomography: Reconstruction With Circular Transducer Arrays," S. J. Norton and $M$. Linzer, Ultrasonic Imaging, 1 (2) 154-184 (1979).

"Piezoelectric Polymer Transducers," S. Edelman, Proc, Workshop on Sonar Transducer Ma terials, Naval Research Lab. Washington, DC Nov, 1975, 269 282 (Naval Research Lab., Washington, DC 1976)

"New Method for the Experimental Investigation of X-Ray Grids," C. E. Dick and J. W. Motz, Medical Physics, 5 (2) 133 140 (1978)

A Standard Method For Determinung the Efficiency of Fluorescent X-Ray Intensifying Screens: A Status Report,"' R. C. Placious, E. S. Moser, R. S. Holland and F. Masi, SPIE 127, Optical Instrumentation in Medicine V/ (1977).

"'X-Ray Magnifier."' W. J. Boettinger, $H$. E. Burdette and M. Kuriyama, Rev. Sci. Instr., 50 (1) 26 30 (1979).

Practical Applications of Neutron Radiography and Gaging" (H. Berger, ed), ASTM STP 586 , $320 \mathrm{pp}$. (Am. Soc. Testing and Materials, Philadelphia, PA 19103. 1976)

"The Technological Development of Neutron Radiography," D. A. Garrett and $H$. Berger, Atomic Energy Rey. 15 (2) 125 142 (Int. Atomic Energy Agency, Vienna, 1977)
Consideration of Fracture Mechanics Analysis and Defect Dimension Measurement Assessment for the Trans-Alaska Oil Pipeline Girth Welds" (H. Berger and J. H. Smith, eds.), NBSIR 761154,2 vols. (1976). Order from Nati. Tech. Information Service, Springfield, VA 22151 as PB260400 and PB260401

'Levels of Illumination and Legibitıty,"' G. T. Yonemura, W. N. Benson, R. L. Tibbott, NBSIR 77 1306 (1977). Order from Natl.

Tech. Information Service, Springfield, VA 22151

'The Measurement and Characterization of Surface Finish," $R$. D Young, E. C. Teague, Chapter 2 in Properties of Electrodeposits, Their Measurement and Significance (R. Sard, H. Leidheiser and F. Ogburn, eds.), 22-49 (Electrochem. Soc., Princeton, NJ 1975).

'Magnetic Leakage and Force Fields for Artificial Defects in Magnetic Particle Test Rings," L. J. Swartzendruber, 12th Symp. on NDE, Southwest Research Institute, San Antonio (1979).

'Ouantitative Methods of Wear Debris Analysis," A. W. Ruff. WEAR, 46 (1) 263-272 (1978)

"Microcalorimetric Study of Cardiac Pacemakers and Batteries," E. J. Prosen, J. C. Colbert, Semiconductor Measurement Technology: Reliability Technology for Cardiac Pacemakers II Workshop Report (H. Schallt, e NBS Spec. Publ. 400-42, 16-18 (1977). Order from Govt. Printing Office, Washington, DC 20402 as C13.10:400-42

'Thermal Mapping of Transistors with a Laser Scanner," D. E. Sawyer, D. W. Berning, Proc. IEEE Letters 64 (11), 1634-1635 (1976).

"Nondestructive Tests to Determine Concrete Strength: A Status Report, "J. R. Clifton, NBSIR 75 729 (1975). Order from Natl. Tech. Information Service, Springfield, VA 22151 as PB246858

\section{LC 1080}


